\title{
Developing work culture environment with high performance work organization
}

\author{
K. Ashok Kumar \\ Newton's Institute of Engineering College, Macherla Guntur District, Andhra Pradesh, India. \\ E-mail: yoursashok1984@gmail.com.Tel: 9490456140. \\ Accepted 7 May, 2012
}

\begin{abstract}
This paper by Ashok Kumar and Dr. Ch. Bala Nageswara Rao Director SSM, Channai; focuses on the need for creating strong work cultures for developing high performance work organizations. According to him, restructuring through formation of autonomous work groups, reducing hierarchies, relocation, creating awareness about the existing work culture and acculturation are some of the processes by which a strong work culture can be developed.
\end{abstract}

Key words: Culture, work groups, development, performance, work organization.

\section{INTRODUCTION}

Recent studies on organizations suggest that high involvement and high performance organizations have strong work cultures (Peters and Waterman, 1982; Deal and Kennedy, 1982; Sinha, 1990). Frost et al. (1985) argued that economic models and assumptions have failed to explain decline in organizational productivity and performance in North America. They suggest that the culture prevailing in an organization and possibly the society to which it belongs can provide greater insight into aspects of organization performance. Louis (1985) has observed that the strong work culture prevailing in Japanese organizations creates desirable attitudes and behaviours in their members and influences their commitment and productivity. A strong work culture also reduces the need for structural controls.

Literature on organization development discusses several interventions which can be used for developing work cultures (French and Bell, 1978; Margulies and Raia, 1975; Beer, 1976). This paper reviews and examines some of the organization development interventions in the Indian context in the framework of developing work culture and discusses issues of leadership and the role of training and trainer in developing work culture.

\section{MEANING OF WORK CULTURE}

Louis (1980) defines a group's culture as a set of understandings or meanings shared by a group of people. The meanings are largely tacit among members, clearly relevant to the particular group and are distinctive to the groups which are passed on to new group members. Four points need emphasis in this context.

First, an organization consists of work groups structured around products, services, technologies or a combination of them, and therefore, different work groups in an organization may have different work cultures. Second, being a learnt behavior, if an organization so desires, it can facilitate various work groups to change and develop new work cultures. Third, the systems and processes which facilitate a social group to continue or change its culture can also provide insight into how new work culture can be developed in a work organization. Finally, since organizations are hierarchical, they delegate differential formal power at various levels. This in turn creates expectations that people in position of power will take initiative for developing and institutionalizing functional work cultures.

\section{RESTRUCTURING PROCESS}

This is one of the intervention mechanisms to develop new work cultures. An organization structure defines roles and responsibilities and expected work behavior from different work groups. The process of restructuring can thus redefine roles and responsibilities and can 
facilitate changing work behavior and work culture.

Formation of autonomous work groups, reducing hierarchies and converting large monolithic organization structures into centers of excellence and relocating them are some of the approaches in restructuring used in Indian organizations. We discuss some of the experiences subsequently.

\section{Formation of autonomous work groups}

Formation of autonomous work groups in an organization is the consequence of successful implementation of socio technical systems as evolved by the Tavistock Institute of Britain. The socio technical systems approach attempts to create a better fit between a social system and the technology used by it. Experiments in UK coal mines and Indian textile weaving mills had resulted in improved productivity, safety and morale (Trist et al., 1965; Rice, 1958).

In the Indian context, we can examine the case of Hindustan Aeronautics Limited, a public sector Enterprise, which has successfully implemented the concept of autonomous work groups both in manufacturing as well as in assembly shop.

A manufacturing shop in one of the divisions was responsible for producing about 3,000 types of standard parts such as nuts, bolts, washers, etc. Invariably, some parts were found to be in short supply which adversely affected production activities in assembly and overhaul shops. The shop was originally organized on the principle of process layout. This layout was later changed to cellular manufacture resulting in the formation of 14 cells. Every cell was allotted a number of parts, following similar production processes. In addition to workmen, a supervisor, a planning person and an inspector were assigned to each cell.

After a brief period of adjustment, it was observed that shop productivity had improved substantially and that there was no shortage of standard parts. Moreover, there was considerable reduction in the rate of rejection, through-put time and work-in progress. This technological restructuring led to changes in the functioning of various social groups of the shop. Being responsible for a welldefined common task, group members of a cell felt a greater identification with each other and worked as a team. The improvement in the quality and the quantity of intra-group communication helped the employees to discuss production-related technical problems and to improve the product quality.

Similarly, the total task of assembling an aircraft was restructured and was divided into six autonomous modules. A group of workers representing different trades and skills was grouped together and made jointly responsible for a module. Prior to formation of these work groups, a first line supervisor was required to coordinate amongst workers from different trades, resulting in delayed cycle time and idle man hours. After the restructuring, the group members worked as a team and took the responsibility for intra-group coordination. This, in turn, led to improvement in work planning, reduction in cycle time and improvement in product quality.

Thus, autonomous work groups made the social groups in the organization as learning groups. By being part of such autonomous work groups, employees worked as team members and learned to develop team spirit. They also learned from each other task-related abilities and skills. Thus, by being together, workers started behaving differently and developed new attitudes and work culture. Such outcomes probably once again validate Bern's proposition (1970) that "behaviour causes attitudes."

An important aspect related to creation of autonomous work groups is the management of reward systems as it encourages members to use a variety of skills and thereby enables them to experience job enrichment. Having established a close identity with a well-defined task and having exclusive group responsibility for a task completion, members of an autonomous work group become aware of their increased contributions towards task completion. In the absence of higher rewards, therefore, members are likely to experience inequity which may lead to reduced inputs from them.

Locke et al. (1976) have reported that as a consequence of job enrichment, employees had expectations of higher rewards in the form of extra promotions and larger salaries. However, when extra rewards were not forthcoming, workers felt disappointed and no positive attitudinal changes were observed. Thus, a justification exists for making the rewards contingent with creation of autonomous work groups. Group incentives or bonuses can link the efforts with rewards.

Being group rewards and common to all the members, the system also ensures that the member's identification with his group is further strengthened. Senge (1990) has argued that effective learning requires learning in family groups. Takezawa (1982) has found that in Japan, participation in quality circles (family learning groups) has led to the formation of self-administrative groups (Jishukarni Group). Hence, we can logically conclude that Indian organizations which have experimented successfully with quality circle interventions may find it easier to initiate autonomous work groups. Also, such organizations should find it easier to plan for changing work culture, if required.

Studies on quality circles in the Indian context, however (Agrawal, 1988) suggest that non-involvement of immediate superior is one of the major reasons for ineffectiveness of quality circles in most organizations. Because of non-invovlement of immediate superior in quality circles activities, the group does not remain a family group since it has an external facilitator. Also, it becomes a parallel structure to the existing formal structure. As a result of these two factors, quality circles have become dormant. Therefore, this issue needs to 
be addressed to when initiating autonomous work groups.

\section{Minimum hierarchies}

The executives at the middle management level are found to exert considerable influence on the prevailing work culture in large organizations. Often, the top management in large organizations have observed that middle managers do not take responsibility, do not work as a team and avoid taking risks. A study of middle managers in four large Indian organizations by Nilakant and Ramnarayan (1990) reveals that such work cultures at the middle management level are a consequence of routine, fragmented, segmented and repetitive work. Such role erosions at the middle management level are caused due to unplanned growth.

Promotion is used as a part of reward system rather than being used for redefining responsibilities and accountabilities. Further, being time-scale and seniority based, promotions delink performance from growth and contribute to increase in hierarchies. These kinds of tampering with organizational structure by creating additional positions and levels to satisfy growth needs makes an organization less responsive and less flexible.

The decisions get delayed and coordination at various levels becomes more time consuming and difficult, there are suitable alternatives to the hierarchical system of functioning which have been tried out successfully in Indian organizations. The Steel Authority of India Limited, for instance, has reduced the number of reporting levels without reducing growth opportunities. During our personal discussions with the executives from this organization, it was revealed that as a consequence of restructuring, delays in decision making have been reduced and the organization has become more responsive to its environment.

Improvements in the financial performance of the company possibly validate the impact of such HRD interventions. Decentralization and creation of divisional profit centres is another way of reducing hierarchies and increasing the efficacy of middle management.

\section{Relocation}

Relocation is one of the ways of restructuring an organization as it alters an existing social system and thus provides opportunities for creating a new social system and a new work culture. Relocation can also be used to redefine the size of an organization. Relocation as a strategy has been successfully implemented by the Indian Telephone Industries (ITI); a large, multi-divisional, multi-location, public sector enterprise.

Based on a new technology, ITI started a new division five years back and decided to locate it at Hosur. A large number of employees from the Bangalore complex were transferred to the Hosur unit, some of them with promotions. All the employees were aware that they would be learning new technologies. Though a large section of employees at the Hosur unit were transferred from the Bangalore unit and thus were inconvenienced in many ways (such as commuting from Bangalore to Hosur), it could be observed that workers at the Hosur unit were more disciplined, quality conscious and worked as a team.

Interventions such as quality circles were more successful at the Hosur unit as compared to the Bangalore unit. Thus, it could be said that the employees who were transferred valued learning and growth. Also, the management had an opportunity to select employees having values congruent to the new evolving culture at Hosur. The Hosur division had an additional advantage of being much smaller compared to the Bangalore division.

Kanter (1989) has reported that in mid 1980s, Eastman Kodak was able to change its functioning and improve its performance by restructuring its highly centralized bureaucratic system into smaller decentralized divisions. Therefore, we can logically conclude that it is much easier to create desirable work values in a smaller social system as compared to a large unit.

\section{Creating awareness about existing work culture}

People continue to behave in particular ways due to lack of awareness about their behavior and its dysfunctional effects. Creating awareness about their existing work behavior and exposure to desirable work cultures can facilitate change. This was successfully tried at Hindustan Machine Tools Limited (HMT), a pioneer in machine tool industry in India, which was implementing systems for total quality management (TQM) in collaboration with the World Bank. The company's consultants who were in charge of implementation of TQM went round the plant and took photographs of various work areas representing the effect of existing work systems. Later, they organized an exhibition of those photographs. It is reported that the employees working in those work areas visited the exhibition, became aware of the need for improvement in various areas and consequently implemented many improvements in their work settings.

Awareness about alternative functional work cultures can also be an important input for bringing change. Employees in small groups can be taken for visits to plants/divisions having desirable work culture. Personal exposure to alternative work cultures can initiate the process of change in a given work culture.

\section{Acculturation}

A social system, over time, evolves its own culture. New entrants to an organization should be acculturated in the existing culture. This process makes new entrants aware 
of the values, beliefs and practices prevalent in a given organization. It also makes them aware of what is expected of them in terms of their behavior and what they can expect from the organization. Thus, the process of acculturation facilitates in defining expectations of both parties and makes them aware of the underlying psychological contract. Murthy and Gregory (1989) have reported how a laboratory setting was used to facilitate the acculturation process at Sundaram-Clayton (TVS/SCL) for 29 management trainees. The objectives of the workshop were:

1. To impress upon them the need to appreciate the corporate reality of TVS/SCL group.

2. To generate sensitivity to various organizational processes that reflect the cherished values and vision of the leaders; this will help in developing coping and compromising skills by the individuals.

3. To develop a spirit of team work using the principles of trust, openness and sharing of resources without personal bias.

According to the authors, the workshop provided opportunities to the management trainees to clarify many aspects from the top management. As a consequence, they became comfortable with the organizational norms. Most of them, in fact, continued to work for the organization.

\section{TRAINER'S ROLE IN DEVELOPING WORK CULTURE}

A person in a leadership position needs to be aware of his personal values, existing organizational values as held by collectivities, and desirable organizational values which can facilitate the organization to achieve its objectives. The personal values of the leader may be appropriate to be institutionalized as organizational values. However, the leader needs to involve the collectivity in examining the existing organizational values and redefining those values, if required.

A collectivity which has no role to play in defining organization values may not own the responsibility for institutionalizing desirable organizational values as perceived by the person in power. Thus, the person in power and members of a collectivity may continue to operate from their own value premises. Such situations contribute to conflicts and if those conflicts do not get resolved, communication amongst various parties breaks down and alienation takes place. It creates a work culture where many groups may work as islands, being part of the same organizational boundaries but still independent of each other. It is here that a trainer can play a critical role in developing work culture.

Developing work culture is a process of planned change and, therefore, a trainer should work as an effective internal change agent. In addition, a trainer needs to ensure that training and development processes initiated lead to empowering of the participants to plan for and implement the change in their respective work settings.

Agrawal (1991), based on his experiments on transfer of learning, has argued that 'diagnostics' is the first and possibly the most important step in ensuring that training and development leads to empowering and change.

Through diagnostics, both the participants and the trainer become aware of work related problems and difficulties as experienced by the participants. This also becomes the basis for defining the learning needs of the participants. A trainer (based on personal experiences and observations of the author) can use the diagnostics data to redesign a need based training programme. The participants can keep their focus in the programme to get answers to those diagnostics problems. We elaborate the process of changing work cultures through training and development.

Work related learning and awareness about how learning can be used in work setting can also be empowering (Agrawal, 1991). Participants in a training programme can be encouraged to keep a record of what is being learnt by them and how it can be used in their respective work settings. In addition, based on the diagnostics and learning from a programme, the participants would need to be facilitated to develop 'action-plans' for implementation.

Feedback about implementation of the action-plan can be a way of refreezing the change. Thus, the diagnostics, learning review and action planning can link training and development efforts with plans for developing new work cultures.

\section{REFERENCES}

Beer Michael (1976). "The Technology of Organization Development" in Marvin D Dunnette (ed) Handbook of Industrial and Organizational Psychology. Chicago: Rand MC Nally College of Publishing, pp. 937994.

Bern Daryl J (1970). Beliefs, Attitudes and Human Affairs. Belmont: Brooks/Lole Publishing.

Deal Terrence, Kennedy Allen (1982). Corporate Culture: The Rites and Rituals of Corporate Life. London: Penguin Books.

French Wendell L, Bell Jr, Cecil H (1978). Organization Development. Englewood Cliffs, N J: Prentice-Hall.

Frost Peter J, Moore Larry F, Louis, Meryl Reis, Lundberg Craig C, Martin, Joanne (1985). Organization Culture. New Delhi: Sage.

Kanter Rosabeth Moss (1989). When Giants Learnt to Dance. London: Unwin Hyman.

Locke EA, Sirote D, Wolfson AD (1976). "An Experimental Case Study of the Successes and Failures of Job Enrichment in Government Agency." J. Appl. Psychol., 61: 701-711.

Louis Meryl Reis (1985). "Organizations as Culture-bearing Milieux" in L R Pondy et al. (eds) Organizational Symbolism. Greenwich, CT: JAI, quoted in Louis.

Margulies Newton, Raia Anthopy (1975). Organizational Development: Values, Process, and Technology. New Delhi: Tata McGraw-Hill.

Murthy PVR, Gregory JX (1989). "Acculturation: An Initiative in Induction Trainees" in Towards Organizational Effectiveness through HRD. Jamshedpur: National HRD Network, pp. 7-17.

Nilakant V, Ramnarayan S (1990). "Manager in the Middle: A Case of Underdevelopment and Underutilization," Vikalpa, 15(2): 3-12.

Peters Thomas J, Waterman Robert Jr H (1982). In Search of 
Excellence. New York: Harper \& Row.

Rice AK (1958). Productivity and Social Organization: The Ahmedabad Experiment. London: Tavistock.

Senge Peter M (1990). The Fifth Discipline: The Art and Practice of the Learning Organization. New York: Doubleday/Currency.

Sinha Jai BP (1990). Work Culture in the Indian Context. New Delhi: Sage.
Takezawa S (1982). Improvements in the Quality of Working in Three Japanese Industries. Geneva: ILO.

Trist EL, Higgin GW, Murray H, Pollock AB (1965). Organizational Choice. London: Tavistock. 